\title{
The rural super city - Central Lancashire New Town.
}

\author{
Victoria Jolley ${ }^{1,1}$ \\ ${ }^{1}$ Manchester School of Architecture, UK.
}

\begin{abstract}
From 1950 rural Lancashire, in England, became the focus of a major renewal scheme to accommodate population overspill from nearby cities of Liverpool and Manchester. Over a period of 15 years the initial proposal for a series of self-contained new towns progressed into an ambitious scheme for a single polycentric "supercity" for 500,000 people. Known as Central Lancashire New Town and designed by RMJM, this part-realised development was the last and largest New Town designated under the 1965 Act. Its theoretical urban pattern, which followed new and proposed infrastructure, was unique. Based on a ladder system this straddled rich agricultural land and declining post-industrial townscapes to unify and expand existing settlements with the aim of generating prosperity on a sub-regional scale. CLNT was not completed but its planning phases can be traced across Lancashire's urban and rural landscapes by built communications networks and city-scale public and civic buildings. Referencing three different new town typologies this paper will outline the project's evolution and identify the impact that designing for the motorcar and future change had on the provision of green space. This research has been undertaken using previously "closed" archival resources and architectural journal and local press articles.
\end{abstract}

\section{Introduction}

Designated in 1970 Central Lancashire New Town is significant because it was the last and largest of the third generation new towns proposed in Britain between 1967 and 1970 and it demonstrated an unprecedented application of the New Town Act. Set within rural Lancashire, CLNT is a part-realised sub-regional complex based on an interconnected series of urban townships. Inspired by the context's poly-centricity, it focused on existing small towns and villages surrounding Preston, Chorley and Leyland and involved the creation of substantial new communities as well as the controlled expansion of existing settlements (Figure 1). Prepared by Central Lancashire Development Corporation following extensive consultation, its strategy for delivery over a period of 30 years was released prior to a public inquiry as an Outline Plan in 1974 [1: 9]. This master-plan, prepared by Robert Matthew Johnson Marshall and Partners, accommodated a predicted population increase from 253,000 in 1966 to 503,000 in 1991 over 51,460 acres, 44,187 acres of which had been identified as suitable for development. Four key criteria needed to be satisfied - the integration of

\footnotetext{
${ }^{1}$ Corresponding author: v.jolley@mmu.ac.uk
} 
new and existing developments to promote urban renewal including raising the quality of existing development and maintaining a clear contrast between town and country; the phasing of construction in self-contained locations which have appropriate urban character; the integration of all forms of private and public transport, whilst segregating vehicles and pedestrians; land use should accommodate changing circumstances and eventual growth beyond the predicted population intake but not necessarily within the designated area. By the time of its designation several civic and infrastructure buildings had been completed, such as Preston Bus Station designed by BDP (1959-70: Figure 2). Designed as the new town's public transport interchange this demonstrates the scale of the planners' ambition for the area.

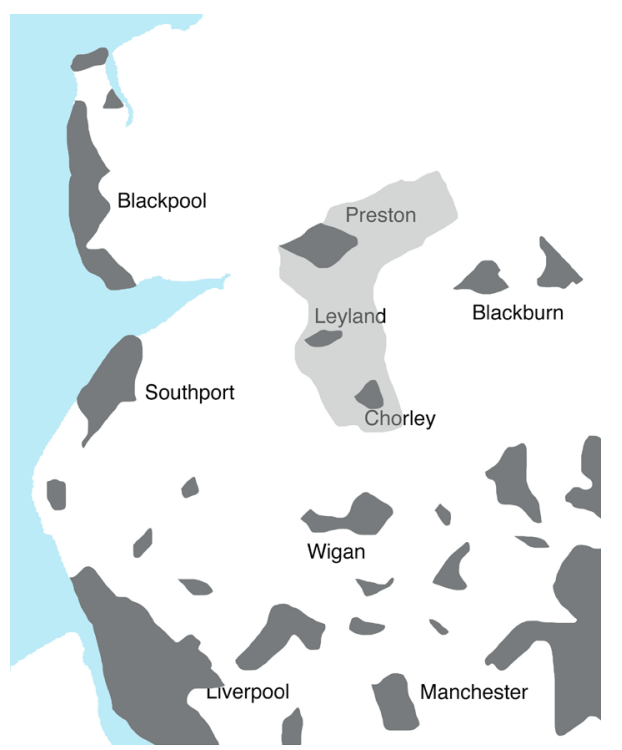

Figure 1: Central Lancashire: poly-centricity and designation area (light grey). (Source: The author)

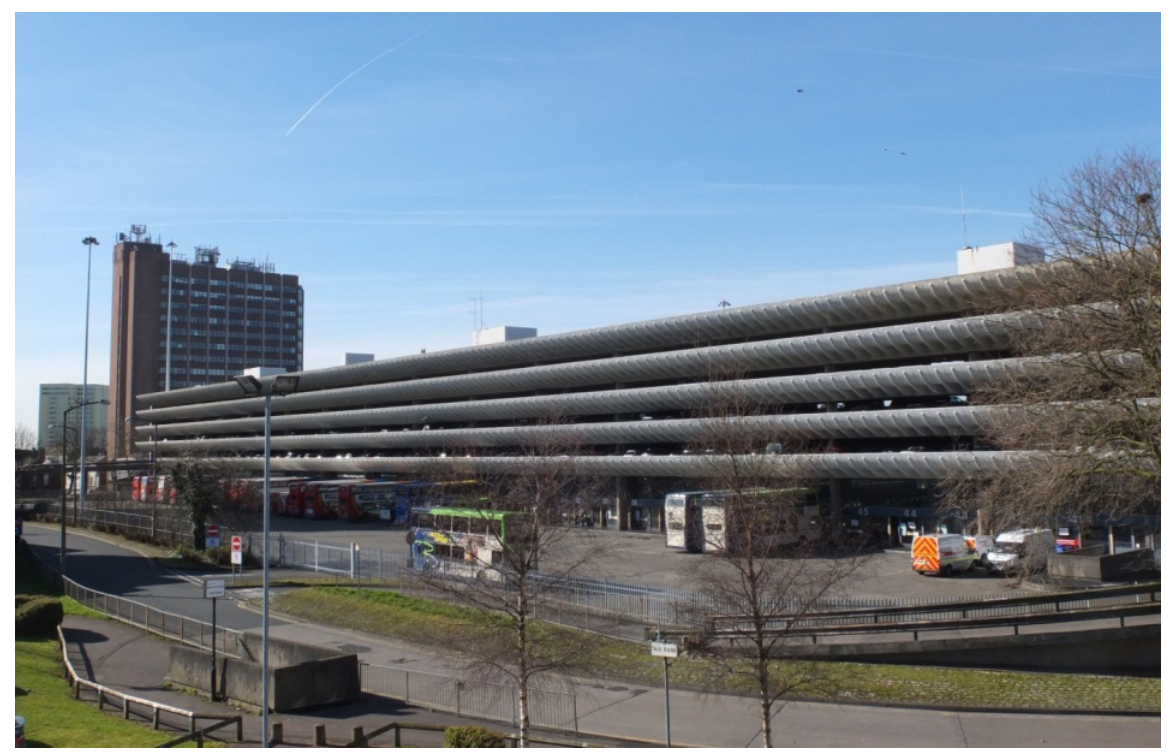

Figure 2: Preston Bus Station, Lancashire, designed by the Building Design Partnership, 1959-1970 (Source: the author). 


\section{New towns in Britain}

The concept of planned decentralization to relieve Britain's inner city overcrowding had been introduced in 1940 by the Barlow Report but it was not until after the Second World-War that the principle of population displacement to facilitate the redevelopment of Britain reignited interest in new towns. A New Towns Committee, established in 1945, considered their delivery and configuration and the passing of two revolutionary Acts - the New Towns Act 1946 and the Town and Country Planning Act 1947, followed. The first series of new towns, the Mark 1's (1946-1961), were low-density, selfsufficient, satellite extensions of their parent conurbations. Early examples, such as Harlow, are refined versions of the Garden Cities of Letchworth and Welwyn - they were limited in size by a fixed pre-determined boundary reinforced by a substantial green belt and offered a complete urban environment comprising housing, employment and leisure. Populations of post-War new towns were generally set at 50,000, an ideal figure proposed by Ebenezer Howard during the early 1900s to ensure sufficient community amenities [2: 10]. Once fully populated, these towns would remain static without growth or change for several generations. Social groups were encouraged by arranging housing to form neighbourhoods, each separated by landscape and each with its own local centre. Their design involved the arrangement of demarcated land uses within the boundary to achieve a logical and aesthetically pleasing town. The town's road network was centralised, connecting its core to the national network. Traffic was free moving but slowed by traffic lights or roundabouts.

In the County of Lancashire, the requirement for a regional strategy to accommodate Manchester's overspill had existed since 1947 and Leyland had been repeatedly identified as a potential Mark 1 new town. It was considered favourable due to its high levels of employment in the motor manufacturing industry, primarily at British Leyland, and land availability to provide residential areas and amenities [3]. It also had good communications to Manchester via north-south rail routes and Lancashire County Council had accepted the principle of a new north-south motorway route passing through Lancashire in 1937. The Special Roads Act of 1949 enabled the construction of motorways and four years later the Minister of Transport proposed the Preston Bypass, the first section, which was part of an expanded road programme. By 1951 the Preliminary Plan for Lancashire included Leyland as one of three new towns across the northwest region and proposed that, by accommodating 32,900 people mainly around Worden Park, Leyland's population could be trebled. Despite being included in the plan the three new towns at Parbold and Garstang, Leyland were later omitted from the approved Lancashire County Council's development plan of 1956. Despite this, construction of the road infrastructure continued and the Preston By-pass opened in 1958 [2] followed by the second section, the Lancaster By-pass, two years later [4: 4].

The Mark 1 new towns' low-density layouts proved too suburban in character and their insufficient urbanity was criticised as achieving little architectural effect. The next series, the Mark 2s (1961-1966), became larger, denser and intensified use. Cumbernauld in Scotland, characterised by its highly centralized plan, multi-level pedestrian decks, extensive road network and the elimination of neighbourhoods is an iconic example. Studies into motor transport coincided with the design of the early Mark 2 towns, which aimed to incorporate highway design to avoid congestion for future traffic predictions even at peak times. The need to design for mobility inspired a shift away from single-centred satellite new towns with clearly defined boundaries to the countryside, to a more regional approach that allowed for future growth and change. Regional or metropolitan solution popularised, based on constellations of towns and 
cities. The new town could now be an interdependent node that could grow and accept changes to land use. This had a drastic impact not only on the treatment of its surrounding landscape but also the distribution of its functions. Neighbourhood concepts were abandoned and layouts that encouraged freedom and dispersal or vehicular and pedestrian movement became favourable. To achieve this transport networks had to provide uniform accessibility throughout the designated area. One solution, advocated by Richard Llewelyn-Davies, designer of Milton Keynes, was the grid-iron network for the primary transport system as it readily permitted expansion and also for pedestrian routes leading to the town centre and sub-centre [5:3].

\section{Third generation new towns}

The third generation new towns (1967-1970) explored the potential of multiple urban or neighbourhood centres to reinforce unity. Milton Keynes (1967) and Central Lancashire New Town (1970) are two examples that adopted this principle through different urban diagrams. Inter-related growth was explored in Lancashire by exploiting the region's existing towns' interdependency and expanding or strategically injecting centres along key communication routes to ensure residential and industrial areas were distributed to minimise peak journeys. Proposals were based on the work of Scottish architects Hugh Wilson and Lewis Womersley who, by experimenting with forms of linear expansion at Northampton (1968), had promoted a three-strand system based on wide bands of development along lines of communication. In 1964 the County Planning Officer had prepared a "Preliminary Technical Report on the Future of Central mid-Lancashire" that focused on the Preston-Chorley-Leyland area [6]. By 1965 the new M6, then the longest section of continuous motorway in the country, had been extended to 111 miles and spanned three counties from south Stafford to north of Lancaster [7]. Forton Service station designed by T. P. Bennett and Sons, 7 miles north of Preston, opened just before the motorway's completion. This early example of transport architecture, with its bold form that contrasts with the rural landscape, is a monument to mobility and captures the pioneering spirit and excitement of road transport during the 1960s. Its landmark tower, originally designed to be 33 metres high but reduced to 20 metres at the request of the planners, cantilevers at the top to provide a sun terrace and restaurant [8]. It was the second services in the Central Lancashire New Town area, the first being Charnock Richards, south of Chorley, designed by Terence Verity and Associates in 1964.

Similar to Ebenezer Howard's utopian objectives, the preliminary report described a pattern of land use that aimed to provide well-positioned and sufficient industry, open space, compact amenities and public services. Journey times could be limited to 30 minutes to open country, 20 minutes to work and 10 minutes to local shops and school. The following year Richard Crossman, then Minister of Housing and Local Government, commissioned Robert Matthew Johnson Marshall and Partners (RMJM) to develop the technical report and undertake preliminary studies for a new town at central Lancashire. Entitled Study for a City, the report marks a long evolutionary process and period of consultation to determine the location and form of the new town as well as its impact on adjacent settlements.

CLNT's sub-regional strategy underwent three stages of refinement. Initially RMJM's proposals are a diagrammatic, represented out of context as a theoretical urban pattern that aimed to balance the growth of employment, housing and transport and reinforce the social, economic and geographical characteristics of Lancashire. The notional urban pattern was based on four community types of differing scales: the entirety, the city (300,000-500,000 people); townships $(60,000-80,000)$; districts 
$(15,000-18,000)$ and localities $(4,000-5,000)$. Arranged as a linear ladder-like complex the initial format comprised seven inter-connected townships connected by a threestrand system of dual carriageways and public transport routes to promote evenly distributed free-flowing travel with minimal congestion. A framework of green belts and woodland defined each community's individuality as well as create visual barriers between housing and employment areas. This also provided a network of footpaths between open spaces and the countryside. RMJM proposed a multi-centred growth strategy to disperse economy, employment and amenities throughout the city, giving each area a clear function and equal potential. This was thought to be advantageous as the array and number of facilities could increase in line with population growth. Dual carriageways linked the township's residential and industrial areas to the motorway and an express bus route joined the centres. Within the townships distributor single carriageways enabled lateral and radial vehicular movement between industrial and residential quarters and the town centre. This was supplemented by local public transport supported by a town's central interchange with car parking. Multiple pedestrian routes linked the town centre, its park, districts and outer recreational space. Infrastructure also separated the township's inner core (the nucleus occupied by the town centre, parkland and smaller community districts with local amenities) from an outer ring of further districts including industry located on the periphery.

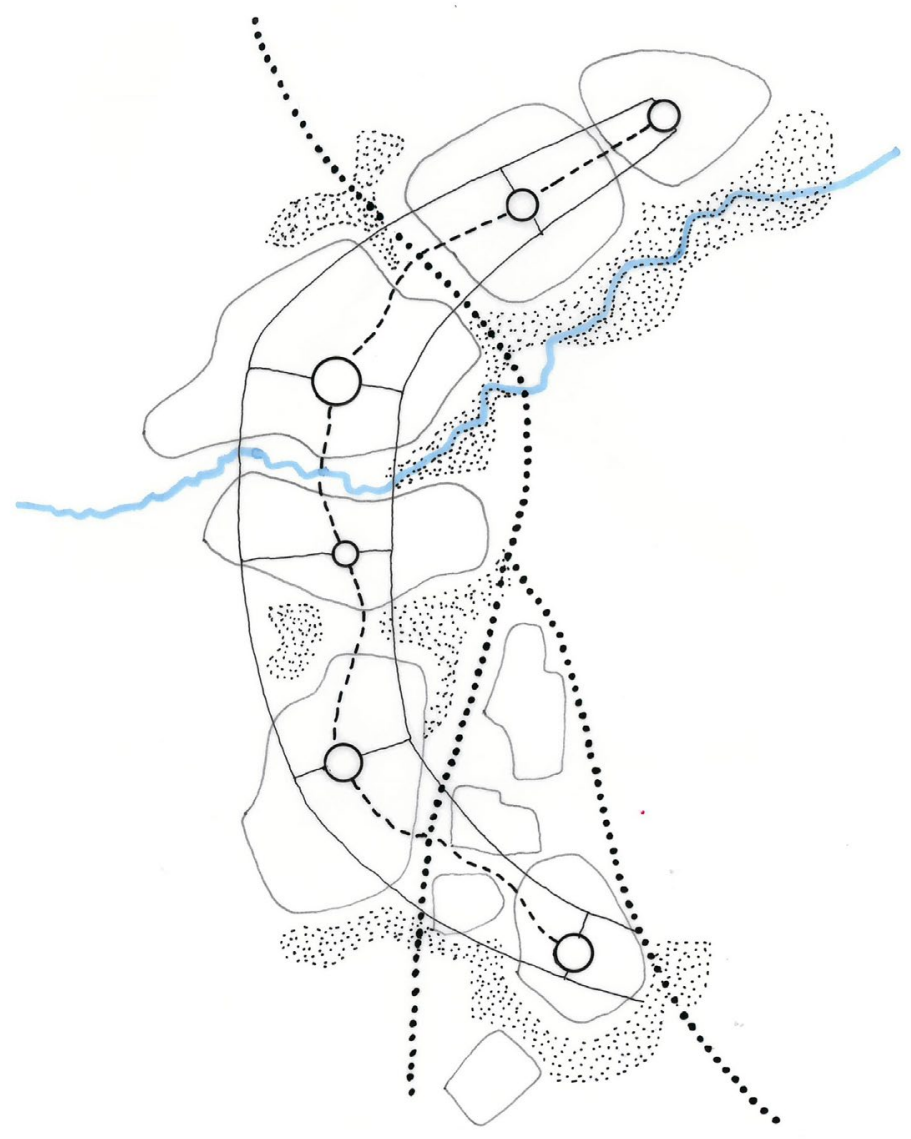

Figure 3: Central Lancashire New Town: theoretical diagram, RMJM. 
RMJM's initial scheme for CLNT adopted Wilson and Womersley's initial approach for industry and infrastructure and also based the districts' layout on a superblock model that segregated pedestrian and vehicular movement. Each district had centrally positioned local community facilities such as schools, nurseries and greens that were accessed by footpaths and public transport, with industry positioned adjacent to main roads. New urban housing respected the urban grain and included blocks of two-storey maisonettes mixed with smaller units, concealed ground-floor car parking and pedestrian access above. Similar to Hook, the challenges of undulating rural landscape, such as valleys and watercourses, would be overcome by spanning a network of pedestrian decks and express bus routes across existing topographical features. New recessed service roads would carry heavy transport.

The clarity of the notional city diagram became diluted when applied to existing subregion's conditions (Figure 3). The seven townships span between Longridge and Chorley with Preston as the main administrative, retail and service industry core and transport interchange. To the east, beyond the M6 motorway two greenfield new towns at Grimsargh and Longridge would accommodate 122,000 people, a significant population increase. These would specialise in education and recreation with Grimsargh also being a centre for welfare and Longridge an entertainment hub. South of Preston, the expansion of Walton would provide a further township for administration and education. Chorley's population would increase to 51,000 to become a culture and entertainment centre and Leyland, which RMJM identified as having most potential to expand and acquire new functions, would increase to 70,000 , to become an education zone also requiring a new social and shopping area, possibly outside the present urban area. A lower density expansion at Cuerden would form a recreation centred district. The study concluded the area was capable of accommodating around half a million people.

In November 1973, the Development Corporation published a draft outline plan that required £900 million investment (at 1973 prices) from both private and public funders. 72,000 new homes were to be built in villages of about 3000-5000 people, grouped into districts of approximately 20,000. Substantial recreation areas were planned for the Ribble and Lostock Valleys including facilities for watersports, equestrianism and a zoo. These proposals then progressed into an outline master plan published in 1974, which was based on providing seven new district centres and eight new major employment areas across five townships (Grimsargh, Preston, Walton, Leyland and Chorley) by 2001. Facilities are not uniformly distributed, instead they are allocated according to hierarchy with Preston, Chorley and Leyland being prioritised.

The study of theoretical diagrams to manage growth was hindered in 1976 when the national funding for new towns was revaluated as Ministers were concerned that inner city areas were starting to suffer economically. As a result, CLNT's population increase target significantly reduced to 23,000 people. During the 1980 s new towns were privatised and CLNT's Development Corporation was dissolved at the end of 1985. Although Central Lancashire New Town's part realisation was not as initially conceived, its theoretical model is relevant because it addressed the planning of a sub-region, rather than a single town or plot, and allowed for its future growth. Significantly its ambition was to provide a large-scale development composed by an inter-related series of self-contained communities, each with a clear identity or function, separated by a network of green space. Its presence today can still be traced by its legacy of its cityscale buildings scattered across the region. 


\section{Acknowledgments}

This work is a development of a paper presented at the $24^{\text {th }}$ ISUF International Conference, Valencia, 2017.

\section{Brief Resume}

Victoria Jolley joined the MSA in January 2015 and currently leads year two of the BA (Hons) programme. Her PhD, based on Central Lancashire New Town, has fostered an interest in garden cities, new towns and dynamic linear growth strategies. In 2009 Vicky gained a Master of Philosophy by Research focusing on Lee House, Manchester (1927-31), an incomplete tall building that demonstrates the influence of the American skyscraper on 1920s British commercial architecture. On graduating from the University of Manchester and Mackintosh School of Architecture, Vicky practiced in Manchester, working primarily in housing and building conservation sectors.

\section{References}

1. PEARSON, F. 1974. Central Lancashire Development Corporation Outline Plan.

2. LING, A. 1964. "The newest towns", New Society, $9^{\text {th }}$ July.

3. LANCASHIRE ARCHIVES, 1968. Central Lancashire New Town Proposals, file note NTC/4/1/82, $1^{\text {st }}$ February.

4. MINISTRY OF TRANSPORT AND CIVIL AVIATION, 1958. Preston By-pass, $5^{\text {th }}$ December.

5. MINISTRY OF TRANSPORT, 1960. Lancaster By-pass, $11^{\text {th }}$ April.

6. LLEWELYN DAVIES, R. 1966. "Town Design", The Town Planning Review, vol. 37, $n^{\circ}$ 3: 157-8.

DOI: https://doi.org/10.3828/tpr.37.3.g54n016nl31r201r

7. 1963. "Motorways and the landscape", The Guardian, $15^{\text {th }}$ November: 15.

8. CRUICKSHANK, D. 1996. "Forton services: M6 Lancashire 1965-1996", RIBA Journal, vol. 103, n 4: 48-55. 